\section{Brunner's gland hyperplasia: A rare cause of gastrointestinal bleeding}

\author{
Lubna Kamani, ${ }^{1}$ Ravi Raj, ${ }^{1}$ Rabia Ali, ${ }^{2}$ \\ Faisal Siddiqi ${ }^{3}$
}

Departments of ${ }^{1}$ Gastroenterology;

${ }^{2}$ Histopathology; and ${ }^{3}$ Surgery, Liaquat

National Hospital, Karachi, Pakistan

\begin{abstract}
Brunner's gland hyperplasia (BGH) is an unusual entity that presents with large duodenal polyp or mass and rarely causes gastrointestinal bleeding. It is usually asymptomatic and often an incidental finding during the esophagoduodenoscopy (EGD). However, most of the cases are benign. We encounter a 40 years old man who presented in Emergency Room with melena. EGD revealed solitary, large duodenal polyp in second part of duodenum and later histopathological findings were consistent with BGH.
\end{abstract}

\section{Introduction}

Bleeding from gastrointestinal tract secondary to Brunner's Gland Hyperplasia $(\mathrm{BGH})$ is a rarely phenomenon. ${ }^{1}$ It can present from hyperplasia to polypoidal lesion termed Brunner's gland adenoma or hamartoma. ${ }^{2}$ Occasionally these may turn into malignancy. ${ }^{3}$ Patients has wide spectrum of presentation from being asymptomatic in some cases whereas others might present with upper gastrointestinal bleeding or with duodenal obstruction. ${ }^{1,4-8}$ Radiologic imaging and endoscopic findings are often misleading and histopathology of the duodenal polyp or mass is required for definitive diagnosis and management. ${ }^{5,8}$ We present a case of a 40 years old man came in emergency room with melena secondary to a solitary, large duodenal polyp. We also elaborate the clinical presentation, diagnostic workup and prognosis of this disease.

\section{Case Report}

A 40 years old man without known comorbid presented in the hospital with melena for last one week. There was no history of hematemesis or epigastric discomfort. He denied any history of drug intake or addictions. On examination, he looked pale and had tachycardia. Nasogastric tube was passed and the fluid drained was dark coffee ground. Digital rectal examination (DRE) revealed black tarry stool. His initial hemoglobin level was $6 \mathrm{~g} / \mathrm{dL}$. After blood transfusion and stabilization, he underwent Esophagoduodenoscopy (EGD) that revealed a solitary, large (approximately 6 $\mathrm{cm}$ ) duodenal polyp starting from D2 and extending up to D4 (Figure 1). Later CT scan was also performed, which showed similar findings (Figure 2).

As the polyp was large, detailed counselling to patient and family was done regarding option of endoscopic removal or elective surgical removal of polyp, but patient finally decided for latter. So he underwent duodenotomy and polypectomy (Figure 3 ). His post-operative course remained uneventful and he was later discharged from hospital. Histopathology of the resected specimen showed BGH (Figure 4).

\section{Discussion}

Upper gastrointestinal bleeding secondary to BGH is rarely seen. ${ }^{1}$ These are tubulomcinous glands that secrete alkaline mucin which protects duodenal mucosa from acidic $\mathrm{pH}$. These are predominantly found in the mucosa and sub mucosa in the proximal one third of the duodenum. ${ }^{9}$ Amongst all the benign duodenal polyps and masses, $3.9-10 \%$ are $\mathrm{BGH} .{ }^{8}$ It is equally present in either gender. It is usually diagnosed in fifth or sixth decade of life, ${ }^{1}$ though patient that we report here was relatively young. BGH shows a wide range of histopathological findings ranging from extensive proliferation of mucinous glands arranged in the form of lobules, pedunculated adenomatous or rarely as hamartomatous lesions. ${ }^{2}$ The cause of BGH is currently not

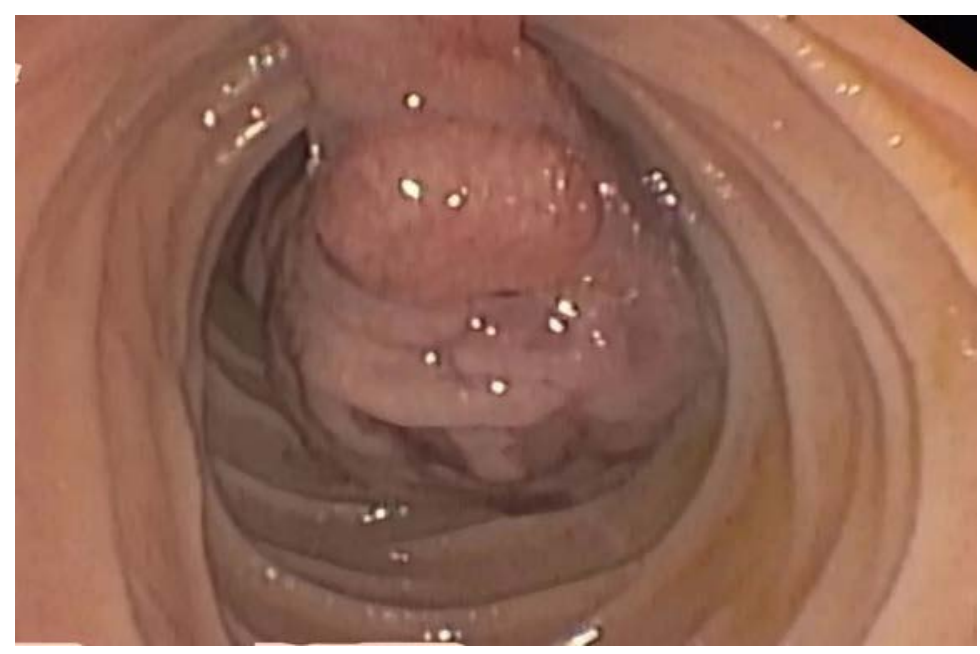

Figure 1. Endoscopic view of polyp before removal.
Correspondence: Lubna Kamani, Department of Gastroenterology, Liaquat National Hospital, Karachi, Pakistan.

Tel.: +92.300.2562141.

E-mail: 1kamani@yahoo.com.

Key words: Brunner's gland hyperplasia; duodenal mass; hematemesis; gastroscopy.

Contributions: LK conceived the idea, final drafting and editing of the manuscript; RR, literature search and writing first draft of manuscript; RA, extensive literature search and re writing of second draft; FS, critical revising the draft and references.

Conflict of interest: the authors declare no potential conflict of interests.

Ethics approval: This manuscript is written according to hospital ethics and all patient identifiable markers are removed.

Informed consent: informed consent was obtained from the patient.

Received for publication: 26 February 2020

Revision received: 11 June 2020.

Accepted for publication: 12 June 2020.

This work is licensed under a Creative Commons Attribution NonCommercial 4.0 License (CC BY-NC 4.0).

(C) Copyright: the Author(s), 2020

Licensee PAGEPress, Italy

Clinics and Practice 2020; 10:1267

doi:10.4081/cp.2020.1267

known, but hypothesis is it might be related to hyperacidity of the stomach. ${ }^{5}$ Another hypothesis is that Helicobacter pylori might play a role in formation of BGH. ${ }^{4}$ Most of the patients are asymptomatic. In symptomatic patients, most common presentation 

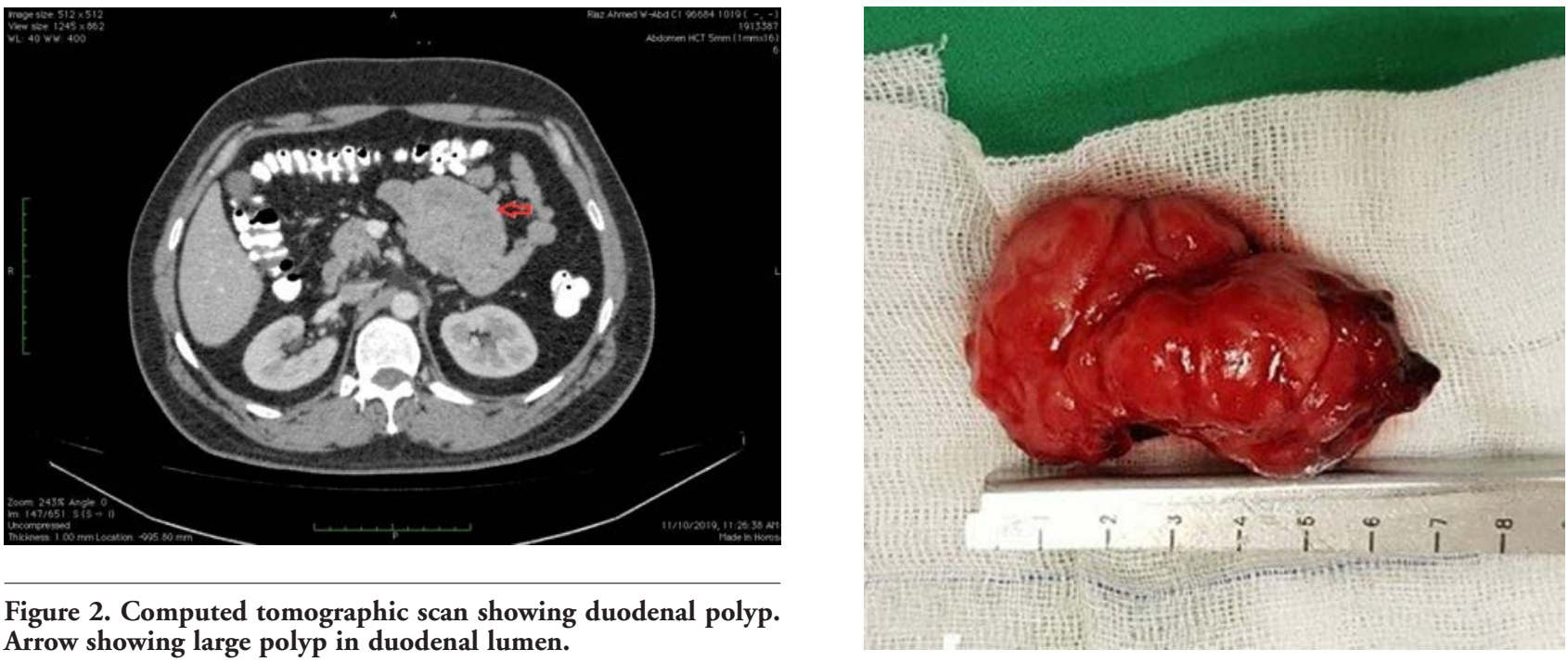

Figure 2. Computed tomographic scan showing duodenal polyp. Arrow showing large polyp in duodenal lumen.

Figure 3. Surgically resected polyp.

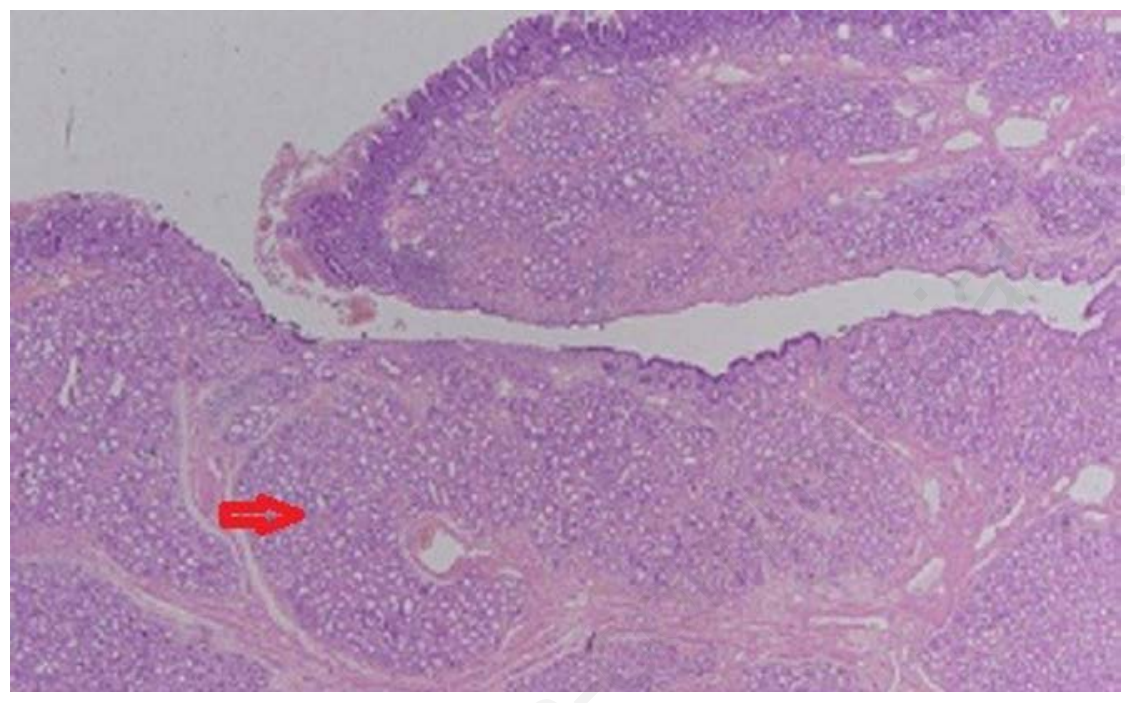

Figure 4. Histopathology of polyp (arrow showing hyperplasia of Brunner's gland).

is gastrointestinal bleeding, either hematemesis or malena and if the polyp size is large enough it might lead to obstructive symptom's such as epigastric pain, vomiting and early satiety. ${ }^{1,4-8}$

Rarely it can lead to bile duct obstruction and cholangitis, acute pancreatitis, small bowel intussusception, and diarrhea. ${ }^{4}$ Occult gastrointestinal bleeding is more common than massive gastrointestinal hemorrhage. Endoscopic examination will demonstrate exactly the size and site of the lesion but its gross appearance often mimics lipoma, carcinoid, gastrointestinal stromal tumors or adenoma. ${ }^{7}$ For definite diagnosis, deeper sub mucosa biopsy is required which can be taken with the help of Endoscopic Ultrasound (EUS). It is also often useful especially before planned endoscopic removal as it gives insight about the depth and vascularity of the lesion. ${ }^{10,11}$ Small lesions can be removed endoscopically safely but larger lesions generally require surgery, ${ }^{1,4-8}$ as in this case.

\section{Conclusions}

$\mathrm{BGH}$ is a rare entity and should be kept in mind while dealing with gastrointestinal bleeding. Overall it has good prognosis.

\section{References}

1. Malik AA, Wani ML, Malik RA, et al. Brunner's gland hyperplasia: an unusual cause of gastrointestinal bleeding. Turk J Gastroenterol 2011;22:419-21.

2. Feyrter F. ÜberWucherungen der BrunnerschenDrüsen. Virchows Arch 1934;293:509-26.

3. Kamei K, Yasuda T, Nakai T, et al. A case of adenocarcinoma of the duodenum arising from Brunner's gland. Case Rep Gastroenterol 2013;7:433-7.

4. Chattopadhyay P, Kundu AK, Bhattacharyya S, et al. Diffuse nodular hyperplasia of Brunner's gland presenting as upper gastrointestinal hemorrhage. Singapore Med J 2008;49:81-3.

5. Janes SEJ, Zaitoun AM, Catton JA, et al. Brunner's gland hyperplasia at the ampulla of Vater. J Postgrad Med 2006;52:38-40.

6. Kibria R, Ali SA, Butt S, et al. Biliary obstruction and pancreatitis caused by diffuse nodular hyperplasia of Brunner's gland. J GastrointestCanc 2009;40:128-30.

7. Kini JR, K H, Pai MR, et al. Brunner's gland hamartoma and hyperplasia. Trop Gastroenterol 2010;31:121-3.

8. Lu L, Li R, Zhang G, et al. Bruner's gland adenoma of duodenum: report of two cases. Int J Clin Exp Pathol 2015;8:7565-9.

9. Mescher A. Junqueira's basic histology: text \& atlas, 13th ed. Chapter 15 Digestive tract. New York: McGraw-Hill; 2013.

10. Terada T. Pathologic observations of the duodenum of 615 consecutive duodenal specimens: benign lesions. Int J Clin Exp Pathol 2012;5:46-51.

11. Hizawa $K$, Iwai $K$, Esaki $M$ et al. Endosonographic features of Brunner's gland hamartomas which were subsequently resected endoscopically. Endoscopy 2002;34:956-8. 